\title{
Mating success and its consequences for population growth in an estuarine copepod
}

\author{
Keun-Hyung Choi, Wim Kimmerer* \\ Romberg Tiburon Center for Environmental Studies, San Francisco State University, 3152 Paradise Drive, Tiburon, \\ California 94920, USA
}

\begin{abstract}
We conducted experiments on mating success of the estuarine copepod Eurytemora affinis in the San Francisco Estuary, USA. The experimental approach was to isolate virgin pairs (one male and one female) in containers varying in volume from 0.03 to $32 \mathrm{l}$ for 2, 4, or $8 \mathrm{~h}$. Mating was considered successful if viable eggs were produced by individual females subsequently incubated for up to $5 \mathrm{~d}$. The experimental data were analyzed by fitting a 3-parameter model to the data to determine the volume search rate of males. Mating frequencies indicated a volume search rate for $E$. affinis males of $7.2 \pm 4.01 \mathrm{~h}^{-1}\left(172 \pm 96 \mathrm{l} \mathrm{d}^{-1}, 95 \% \mathrm{CL}\right)$, about 20-fold higher than that for Acartia hudsonica previously determined by a similar method. A simple population model showed that the critical population density needed to maintain the E. affinis population can be well below the seasonally low abundance of this copepod in the San Francisco Estuary. The low critical density may allow population persistence in an estuary without the production of resting eggs.
\end{abstract}

KEY WORDS: Copepod mating $\cdot$ Allee effects $\cdot$ Population growth $\cdot$ Volume search rate

\section{INTRODUCTION}

Copepods in estuarine and coastal waters face a highly dynamic environment. Variability in abiotic and biotic conditions acting on different time scales can cause seasonal and spatial fluctuations in abundance. Rapid increases and decreases in plankton abundance are common, as are very high or very low abundance values (Ambler 1985, Castel \& Veiga 1990, Liang \& Uye 1996). In particular, many estuarine populations have seasonal lows in abundance when they disappear from plankton samples and reappear several months later (Ambler 1985).

Low population abundance can reduce the rate of encounter among potential mates, leading to low average reproductive rates. The resulting positive feedback ('Allee effect') can accelerate the decrease of population abundance and lead to local extinction (Allee 1931).

Planktonic copepods have at least 2 strategies by which to recover from low population abundance. Spe- cies of coastal calanoid copepods from 5 families are known to produce resting (diapause or quiescent) eggs (Uye 1985), which can allow for quick recovery when conditions improve. Diapause may be induced by unfavorably high or low temperature, photoperiod, crowding, or metabolic products of the copepod population (Marcus 1980, Hairston et al. 1990, Ban 1992, 1994). Also, copepods may produce dormant stages when food is limited (Hopp \& Maier 2005), or as part of a seasonal strategy to take advantage of predictable phytoplankton blooms (Norrbin 1994, Santer 1998). Synchronous emergence from dormancy through environmental signals such as increasing temperature could infuse the population with enough prospective mates to minimize Allee effects.

An alternative strategy for some copepods is to increase the probability of encounter between males and females. Male copepods generally search for females, detecting them through the hydrodynamic disturbance caused by swimming, or, in some species, using pheromone trails to increase detection range 
(Katona 1973, Griffiths \& Frost 1976, van Leeuwen \& Maly 1991, Yen et al. 1998, Kiørboe \& Bagøien 2005). Increasing detection range increases the volume search rate, i.e. the volume searched by males for females per unit time (Kiørboe 2007), which, in turn, reduces the population density needed to prevent mate limitation (Choi \& Kimmerer 2008).

In the present study, we determined the volume search rate for males of the calanoid copepod Eurytemora affinis and assessed the consequences of this rate for population recovery from low abundance. E. affinis ( 1 mm total length) is a dominant species in many temperate estuaries, usually inhabiting lowsalinity areas, and is often associated with the maximum turbidity zone (e.g. Hough \& Naylor 1991, Peitsch et al. 2000, David et al. 2005). The copepod is also an important food source for macrozooplankton such as mysids and many estuarine-dependent fishes such as striped bass Morone saxatilis (Burkill \& Kendall 1982, Meng \& Orsi 1991, Thorp \& Casper 2003). E. affinis is capable of producing resting eggs in response to environmental conditions such as temperature, photoperiod, and crowding (Ban \& Minoda 1992, Ban 1992). Mating behavior and fertilization have been well documented (Heinle 1970, Katona 1973, Katona 1975). Mate finding in E. affinis is asymmetric in that the female produces a pheromone signal and searches primarily for food, whereas the male detects the pheromone and pursues the female (Katona 1973). It is not well understood, however, how this mating behavior relates to population growth (Kiørboe 2007) and, in particular, how dilute the population can become before it is unable to recover.

In the San Francisco Estuary, Eurytemora affinis has historically been abundant and reproductively active throughout the year in the oligohaline or low-salinity zone (0.5 to 6.0 salinity, Kimmerer et al. 1994). However, the abundance of $E$. affinis in summer has declined markedly over the past 2 decades, resulting in frequent reports of absence from net tows in summer (see 'Results'). This decline is associated with the infamous invasion of the 'overbite' clam Corbula amurensis (Nichols et al. 1990), which has greatly depressed food supplies for copepods since 1987 (Kimmerer 2006). In addition, this clam can consume nauplii of E. affinis (Kimmerer et al. 1994), and abundance of the copepod has been depressed since 1987, especially in summer (Kimmerer \& Orsi 1996). Despite the severe decline in abundance during each summer, the population recovers rapidly during the following winter and spring. Production of resting eggs is unlikely as temperature does not become low enough to prompt formation of resting eggs $\left(10^{\circ} \mathrm{C}\right.$, Ban 1992), and oxygen concentrations are rarely below saturation in the lowsalinity zone (see Kimmerer 2004 for data from long- term environmental monitoring programs). Incubation of sediment from the upper estuary during summer and fall 2003 revealed no hatching copepods of any species (J. Durand, unpubl. data). In the absence of resting eggs, the annual population recovery implies that the lowest population density cannot be lower than the critical density for mate limitation.

\section{MATERIALS AND METHODS}

Our overall approach was to conduct mating experiments in which pairs of copepods were incubated in containers of various volumes, and the data were fit to a model of encounter rate (Choi \& Kimmerer 2008). Ancillary experiments were conducted to determine time delays in readiness to mate for males and females. The volume search rate was then applied in a simple population model to determine the minimum population size from which recovery was possible as a function of reproductive rate and survival.

Mating experiments. Copepods were collected from low-salinity waters (salinity of 2 to 5) of the northern San Francisco Estuary using plankton nets of 150 or $200 \mu \mathrm{m}$ mesh, transferred into a large container (20 l) of surface water, and brought into the laboratory. The copepods were fed cultured phytoplankton (Rhodomonas salina and Cryptomonas ovata) to minimize food limitation, and containers were aerated. We used copepods collected from the field for all experiments because of the potential for behavioral changes in copepods reared in the laboratory (Tiselius et al. 1995). Immature males and females (copepodite stages CIV$\mathrm{CV}$ ) were isolated and grown to maturity in well plates (2 ml) with cultured phytoplankton in filtered water from the collection site. Upon reaching adulthood, the copepods were transferred and maintained for at least $1 \mathrm{~d}$ in containers $(\geq 1 \mathrm{l})$ with phytoplankton. The copepods were maintained at constant temperature $\left(15^{\circ} \mathrm{C}\right)$ and ambient salinity (2 to 5), under artificial light for $8 \mathrm{~h} \mathrm{~d}^{-1}$. Throughout all experiments, we observed behavior of the copepods microscopically before, during, and after mating, and used only copepods that appeared to behave normally.

The experimental design was based on previous such experiments with Acartia hudsonica (Choi \& Kimmerer 2008) and results of ancillary experiments (next section). We incubated pairs of unmated copepods for 2, 4, or $8 \mathrm{~h}$ in containers of 6 capacities from 0.031 to $16 \mathrm{l}$, and for 4 or $8 \mathrm{~h}$ in $32 \mathrm{l}$ containers. Twentythree replicate containers were used for each volumetime combination, and the dependent variable of interest was the fraction that had mated. Because observations showed that spermatophores were dropped (and possibly eaten) shortly after mating, the fraction 
mated was determined by the production of one or more nauplii during further incubation after the male had been removed.

One adult male and one adult female copepod were selected at random and introduced into each container. All experimental containers were maintained in the dark to minimize aggregation due to phototaxis. At the end of the incubation periods, copepods were gently strained from the water with a 35 or $53 \mu \mathrm{m}$ mesh net. We verified that both copepods were alive. The mortality of the copepods during the experiments was $<4 \%$, and supplementary incubations were made to compensate for the losses. Females removed from experimental containers were transferred individually into $125 \mathrm{ml}$ bottles filled with $10 \mu \mathrm{m}$ filtered water amended with phytoplankton as above, incubated for up to $5 \mathrm{~d}$, and examined for the presence of nauplii. Further incubation for up to $10 \mathrm{~d}$ of 20 females that had not produced nauplii within the first $5 \mathrm{~d}$ of incubation resulted in no further recovery of nauplii.

Settling of phytoplankton during incubation could alter behavior of copepods during experiments. We therefore tested the effect of motion on mating success during the $8 \mathrm{~h}$ treatments. Half of the small bottles (30 to $500 \mathrm{ml}$ ) were rotated at $1 \mathrm{rpm}$ on a plankton wheel. Half of the containers of water $>500 \mathrm{ml}$ were gently stirred with plastic paddles driven by electric motors. Neither rotation nor stirring had a detectable effect on mating success (chi-square test, $\chi^{2}=0.13$, df $=$ $1, \mathrm{p}=0.72, \mathrm{n}=22$ for rotation and $\chi^{2}=0.05, \mathrm{df}=1, \mathrm{p}=$ $0.83, \mathrm{n}=50$ for stirring). Bottles for 2 and $4 \mathrm{~h}$ incubations were not rotated or stirred because settlement of phytoplankton was less likely during these short incubation periods.

Ancillary experiments. To determine the time lag of mating for females, juvenile (CIV-CV) stages of female copepods were isolated and grown until mature in well plates $(2 \mathrm{ml})$ with filtered seawater amended with mixed phytoplankton comprising Rhodomonas salina and Cryptomonas ovata. The females were examined every $6 \mathrm{~h}$. Each female that had molted to adult was then randomly combined (24 replicates) with 3 males that had been collected from the low salinity waters (2 to 5) in the estuary and maintained 1 to $2 \mathrm{~d}$ in a container $(\geq 1 \mathrm{l})$. Attachment of spermatophores to the females was observed with a dissecting microscope (if necessary, with an inverted microscope) periodically up to $24 \mathrm{~h}$. All of the females mated within $4 \mathrm{~h}$ of incubation.

Juvenile males (CIV-CV) were likewise isolated and grown out in well plates to determine the time lag for mating of males. Upon reaching adulthood, each male was randomly combined with 4 adult females that had been maintained 1 to $2 \mathrm{~d}$ in a container (18 replicates). The females were examined microscopically for the

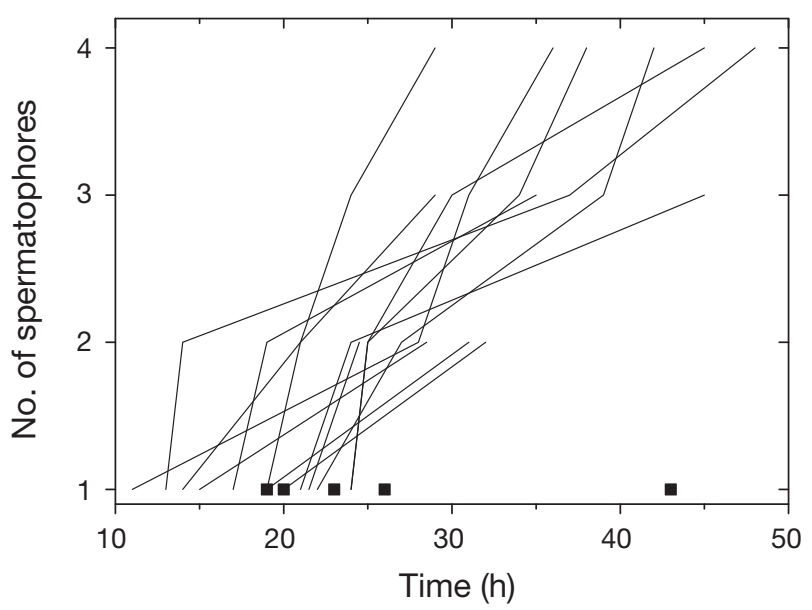

Fig. 1. Eurytemora affinis. Time course of spermatophore production during $48 \mathrm{~h}$ following the final molt to the adult stage of 18 individual males, including 5 that produced only one spermatophore (

attachment of a spermatophore every 3 to $4 \mathrm{~h}$ for $48 \mathrm{~h}$. The earliest mating was observed around $11 \mathrm{~h}$, with a mean time of first mating of $20.6 \mathrm{~h}$. Six males produced 4 spermatophores during the $48 \mathrm{~h}$ incubation (Fig. 1).

To compare mating abilities of males of different ages, males of age $1 \mathrm{~d}$ and males 3 to $4 \mathrm{~d}$ since reaching adulthood were introduced individually to 3 females in well plates as described above. Mating ability, as determined by attachment of spermatophores, was not significantly different between the 2 ages (chisquare test, $\chi^{2}=1.0, \mathrm{df}=1, \mathrm{p}=0.32, \mathrm{n}=22$ ).

In the same manner, 3 males were combined randomly for $24 \mathrm{~h}$ with single females $1 \mathrm{~d}$ after molting or with single females 3 to $4 \mathrm{~d}$ after molting to adult to compare the reproductive abilities of females of different ages. The females were then separated from the males and incubated for $5 \mathrm{~d}$ in $125 \mathrm{ml}$ bottles on a plankton wheel. All of the females $(n=22)$ produced nauplii, showing no difference in fertilization capability between different ages of females.

Mating success model. The probability of successful mating in a pair of copepods is the joint probability of encounter and readiness to mate. We assume random encounters, and in the case of Eurytemora affinis, the detection range and therefore volume search rate is presumably enhanced by the female's release of pheromones. We also assume that males become ready to mate over some time period and that some males may never be able to mate. The model and its additional assumptions were developed for a similar study of mating in Acartia hudsonica (Choi \& Kimmerer 2008) and the model is the same whether mates are detected through hydromechanical cues, as in Acartia species (Bagøien \& Kiørboe 2005), or through pheromones. 
We used the mating model with the experimental data to estimate the effective volume search rate $V_{\mathrm{s}}$. 'Effective' here refers to searches that result in mating and the production of nauplii. Additional parameters are the time constant for readiness to mate $(b)$ and the ultimate fraction that can mate $(\mu)$. The mating model describes the probability that a given female will mate at least once in the time interval $(0, T)$ :

$$
\begin{gathered}
P_{m}(0, T)=\mu\left[1-e^{-b T}-\frac{b}{b-c}\left(e^{-c T}-e^{-b T}\right)\right] \\
C=\frac{V_{s} N_{m}}{V}
\end{gathered}
$$

where $N_{\mathrm{m}}$ is the number of males per volume $V$. The values of the 3 parameters $(b, c$, and $\mu$ ) were estimated from the results of the mating experiments. For these experiments, $N_{\mathrm{m}}=1, V$ is the volume of the container, and the fraction of females that mate is an estimate of $P_{\mathrm{m}}$. Because the data comprised replicate samples in which a pair of copepods either mated or did not, data for each treatment should have a binomial distribution. Therefore, we used a general optimisation procedure, adjusting the parameters $b, c$, and $\mu$ in Eq. (1) to maximize the log likelihood function for a binomial distribution (function optim in Splus, Insightful Corp, Venables \& Ripley 2003). The Hessian matrix from the optimisation procedure was inverted to determine the variances of the parameters and their correlations.

The residual error distribution was compared with that expected from a binomial distribution around the model's predicted probability of mating using a goodness-of-fit chi-square test. We also analysed data and residuals graphically as a check against violation of assumptions and to ensure the mating model gave a suitable fit to the experimental data. Likelihood ratio tests between the model in Eq. (1) and the same model with the parameter $\mu$ fixed at 1 showed a significant difference $\left(\chi^{2}=13, \mathrm{df}=1, \mathrm{p}<0.001\right)$. Therefore, the full model was used in the remaining discussion.

Critical population density model. A simple steadystate population model determining the critical density for zero net growth of a copepod population (Choi \& Kimmerer 2008) is:

$$
A_{\text {crit }}=\frac{m^{2}}{V_{\mathrm{s}}\left(1-F_{\mathrm{f}}\right)\left(\frac{b}{m+b}\right)\left(E F_{\mathrm{f}} S_{\mathrm{e}} S_{\mathrm{j}}-m\right)}
$$

where $m$ is the mortality rate of adults of both sexes, $F_{\mathrm{f}}$ is the fraction of newly molted adults that are female, $E$ is the egg production rate (eggs female ${ }^{-1} \mathrm{~d}^{-1}$ ) by the females that have mated, $S_{\mathrm{e}}$ is the fractional survival of eggs to hatching, $S_{\mathrm{j}}$ is the survival from hatching to adult, and other parameters are as above. If population density within aggregations is greater than $A_{\text {crit, }}$ the population will grow; if it is less, the population will collapse. Note that this equation applies strictly only at the critical population density, and it neglects compensatory density dependence implied in several of the parameters. This is acceptable because we were concerned with dynamics only at low population levels. Other assumptions of this model are discussed by Choi \& Kimmerer (2008).

We applied this model to the Eurytemora affinis population in the San Francisco Estuary. Sex ratio was set at 1:1 $\left(F_{\mathrm{f}}=0.5\right)$. Mortality includes in situ mortality (e.g. due to predation) and losses to advection and dispersion. Residence time of about $30 \mathrm{~d}$ for the low-salinity zone under summer conditions (Walters et al. 1985) translates to a mortality of $0.03 \mathrm{~d}^{-1}$. Egg survival $S_{\mathrm{e}}$ was assumed to be equivalent to female survival because Eurytemora females carry their eggs. Daily mortality of all life stages was assumed equal to that of adult females for simplicity; therefore survival of juveniles is:

$$
S_{\mathrm{j}}=\mathrm{e}^{-m D}
$$

Development time $D$ was previously determined to be $330 \mathrm{~h}$ at $15^{\circ} \mathrm{C}$, and egg development was $33 \mathrm{~h}$ at $20^{\circ} \mathrm{C}$ with a $Q_{10}$ of $2.8 \pm 0.2$ (CL) (W. Kimmerer unpubl. data), which can be applied to development time of juvenile stages if food is not limiting (Corkett \& McLaren 1970). At a summer temperature of $\sim 20^{\circ} \mathrm{C}$ (Kimmerer 2004), the calculated development time is $\sim 8 \mathrm{~d}$, which is similar to the mean of $9 \mathrm{~d}$ at $20^{\circ} \mathrm{C}$ determined by Ban (1994) with plentiful food. Note that extended development time $D$ due to food limitation would have the same effect on the model as increased mortality (i.e. survival through the life stage would decrease, Eq. 3) and is implicitly considered in alternative model runs. The model was explored using the parameters determined from the experiments and varying residence time, other mortality, and egg production rate.

Abundances of Eurytemora affinis in the San Francisco Estuary from 1998 to 2007 were obtained from a long-term monitoring program (Kimmerer \& Orsi 1996). We averaged abundance for each survey in a salinity range of 0.5 to 10 , where $E$. affinis is most abundant. We also determined the minimum reported abundance of any taxon in each survey as an approximate value for the detection limit in that survey.

\section{RESULTS}

Females dropped empty spermatophores soon (generally $<1 \mathrm{~h}$ ) after they absorbed the sperm, although some carried them for $\sim 1 \mathrm{~d}$ without absorbing sperm, and eventually dropped them. Males occasionally dropped spermatophores during attempts to mate, as shown by the lack of cementing material at the tip of the spermatophore. We also frequently observed 


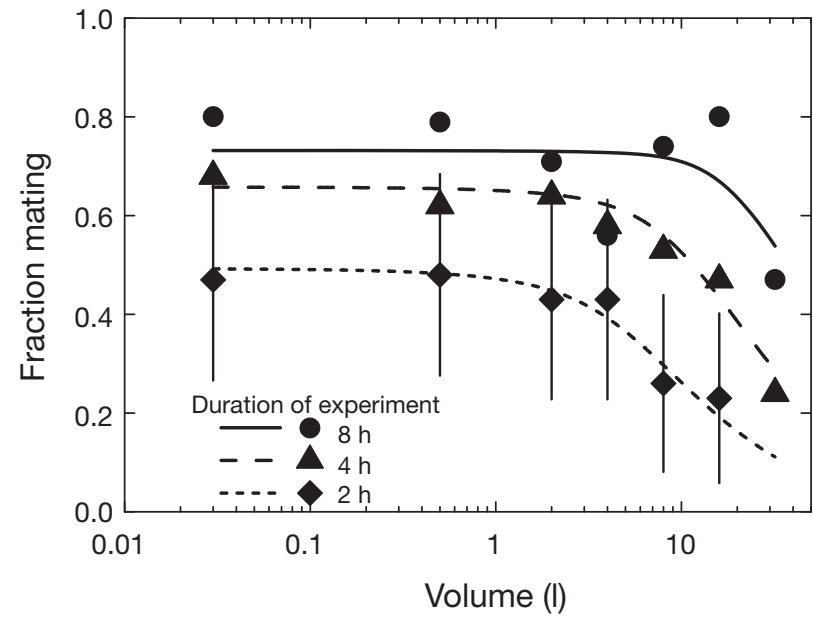

Fig. 2. Eurytemora affinis. Experimental results showing the fraction of copepod pairs that mated as a function of volume for 3 different experimental durations. Symbols: fractions mating out of 23 replicates from the experiment; lines: model predictions (Eq. 1) fit to the entire data set. Error bars: 95\% confidence limits for individual points for the $2 \mathrm{~h}$ experiments only (other points have similar confidence intervals). The largest volume treatment (32 l) was incubated only for 4 or $8 \mathrm{~h}$

Table 1. Eurytemora affinis. Parameters of the mating model determined using Eq. (1) with 95\% confidence limits (fit shown in Fig. 2)

\begin{tabular}{|llc|}
\hline Parameter & Description & Value \\
\hline$\mu$ & $\begin{array}{l}\text { Fraction of males that become } \\
\text { ready to mate }\end{array}$ & $0.74 \pm 0.10$ \\
$b$ & $\begin{array}{l}\text { Rate constant for males to } \\
\text { become ready to mate }\left(\mathrm{h}^{-1}\right)\end{array}$ & $0.55 \pm 0.29$ \\
$V_{\mathrm{s}}$ & $\begin{array}{l}\text { Daily volume search rate }\left(\mathrm{l} \mathrm{h}^{-1}\right) \\
\left(\mathrm{l} \mathrm{d}^{-1}\right)\end{array}$ & $7.2 \pm 4.0$ \\
& & $172 \pm 96$ \\
\hline
\end{tabular}

females from the field population carrying several spermatophores. Eurytemora affinis males can produce up to 3 spermatophores during $24 \mathrm{~h}$ (Fig. 1).

Mating success of pairs of Eurytemora affinis decreased monotonically for all incubation periods as container volume increased above a threshold, in general agreement with the prediction of the mating model (Fig. 2, Table 1). The fit of the model was good, with a correlation coefficient between the predicted and the observed proportion mating of 0.93 (Fig. 3). Mating success in small volumes increased asymptotically with duration of the experiment toward a maximum value of $\mu=0.78$, consistent with the value obtained from the full model $(\mu$, Table 1$)$. Confidence limits around $\mu$ from the full model did not include 1 , indicating that not all of the males were able to mate by the end of the experiments. Half of the males that eventually could become ready to mate were ready in

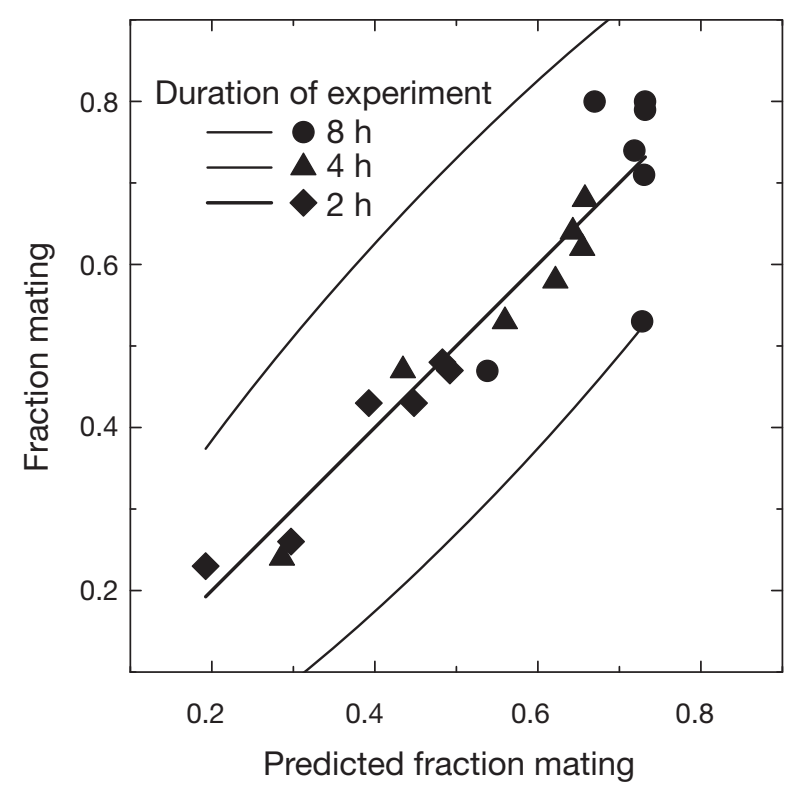

Fig. 3. Eurytemora affinis. Data from Fig. 2 plotted against fitted values. Symbols as in Fig. 2. Lines: 1:1 line and 95\% confidence limits for the fitted values based on a binomial distribution with $\mathrm{n}=23$

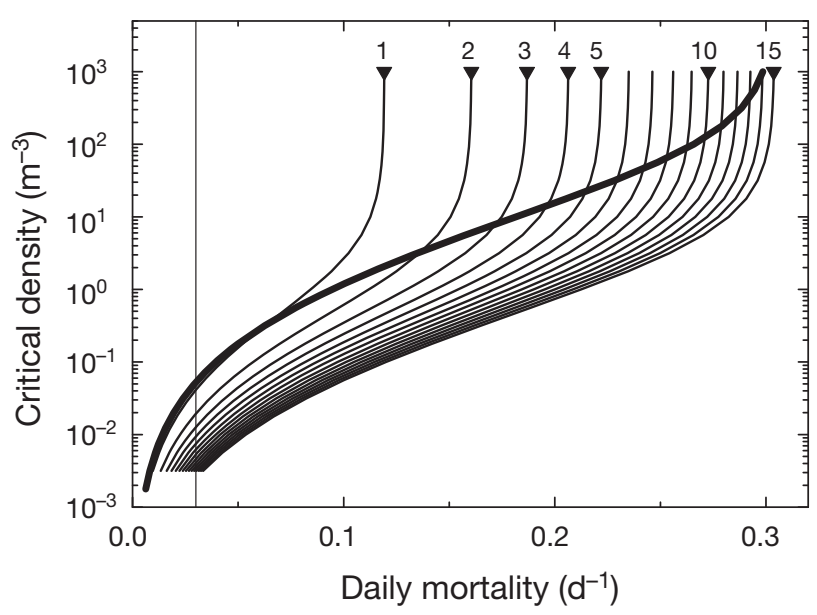

Fig. 4. Eurytemora affinis. Critical density for mating and reproduction as a function (Eq. 2) of daily mortality at various levels of daily egg production by mated females (numbers inside panel are eggs female ${ }^{-1} \mathrm{~d}^{-1}$ ). Vertical line: mortality rate corresponding to zero natural mortality and $3 \%$ daily losses to advection and dispersion. Heavy line: critical density for the volume search rate $\left(8.2 \mathrm{l} \mathrm{d}^{-1}\right)$ calculated for Acartia hudsonica (Choi \& Kimmerer 2008) with egg production of

15 eggs female ${ }^{-1} \mathrm{~d}^{-1}$ and all other parameters unchanged

$1.3 \mathrm{~h}(95 \%$ confidence intervals: 0.8 and $2.8 \mathrm{~h}$, calculated from $b$ in Table 1). The mean volume search rate of the males $V_{\mathrm{s}}$ was $7.21 \mathrm{~h}^{-1}$ or $174 \mathrm{l} \mathrm{d}^{-1}$.

We applied the above mating results to population growth in field situations using the simple population 


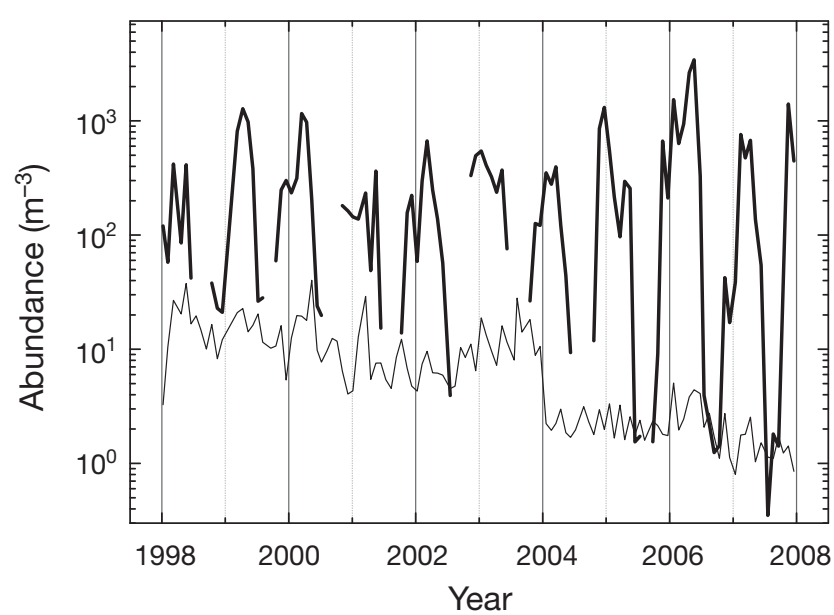

Fig. 5. Eurytemora affinis. Abundance pattern of adults during the last decade for all samples taken in the low-salinity zone (salinity range expanded to 0.5 to 10 to reduce the frequency of missing data). Note that these data were all taken since the invasion of the overbite clam in 1987. Heavy line: monthly maximum abundance of E. affinis. Thin line: monthly mean of the minimum abundance for any taxon, roughly representing the detection limit. Gaps in the heavy line indicate times when $E$. affinis was not detected in these samples. Data from Interagency Ecological Program zooplankton monitoring (Kimmerer \& Orsi 1996)

model (Eq. 2). A self-sustaining population of Eurytemora affinis can have extremely low density if mortality rates are low (Fig. 4). At the high egg production rate, the population was able to sustain higher levels of daily mortality. By comparison, an Acartia hudsonica population with a volume search rate of $8.2 \mathrm{ld} \mathrm{d}^{-1}$ has a critical density about 20-fold higher, with all other parameters the same (Fig. 4).

Actual population density of Eurytemora affinis in the low-salinity zone from 1997 to 2006 was highly variable (Fig. 5). The maximum abundance of adults at stations with salinity of 0.5 to 10 was frequently $<10 \mathrm{~m}^{-3}$, with periods of zero catch at all stations during summers. The minimum non-zero value for any taxon (thin line in Fig. 5) is approximately the detection limit. For example, in summer of 2005 abundance of $E$. affinis dropped to about $1.5 \mathrm{~m}^{-3}$, and then fell to zero when the detection limit was $\sim 1.5 \mathrm{~m}^{-3}$. All that can be said about abundance at that time was that it was likely $<1.5 \mathrm{~m}^{-3}$.

\section{DISCUSSION}

The volume search rate of $172 \pm 96 \mathrm{ld}^{-1}$ estimated from these mating experiments and model is about 20 times larger than the estimate obtained for Acartia hudsonica using the same approach (Choi \& Kimmerer
2008). This higher value is probably due to the greater detection range resulting from the use of pheromones to detect mates in Eurytemora species (Katona 1973), as opposed to the strictly hydromechanical cues used by Acartia spp. (Bagøien \& Kiørboe 2005, Kiørboe \& Bagøien 2005).

To date, the general approach for estimating volume search rates for mates has been by observing mating behavior and swimming speed of the copepods (Yen et al. 1998, Kiørboe \& Bagøien 2005, Kiørboe 2006). In that approach the number of parameters to be determined increases as the geometry of detection diversifies from a simple hydromechanical signal to an elongated pheromone trail or cloud, at least in species with complex swimming behavior (Kiørboe \& Bagøien 2005). Our approach simplifies the calculation of effective volume search rate, directly estimating it from the mating fraction in various volumes of water. This approach glosses over the mechanisms underlying variability in mating success, combining all of the components of mating (Buskey 1998) into a single parameter (effective volume search rate $V_{\mathrm{s}}$ ), but allows for the unequivocal determination of the endpoint. Moreover, if our results are similar to those from behavioral studies, they imply that the probability of mating is largely dominated by the search process, with the other components of mating playing a minor role (Buskey 1998).

Our estimated volume search rate compares well with at least some estimates from behaviorally-based approaches. Probably the most difficult parameter to estimate is the detection distance. In fact, it may be possible to measure only the reaction distance, i.e. the distance at which the male first makes a recognizable movement toward the female (Buskey 1998). With an average swimming speed of $5 \mathrm{~mm} \mathrm{~s}^{-1}$ for males and $2.5 \mathrm{~mm} \mathrm{~s}^{-1}$ for females measured in the laboratory (Katona 1973), the estimated reaction distance of the male to the female Eurytemora affinis based on the effective volume search rate determined here would be $11 \mathrm{~mm}$ or about 8 to 9 times the body length assuming a spherical pheromone cloud (Kiørboe \& Bagøien 2005). Assuming an elongated female pheromone trail would require more parameters to estimate reaction distance, but may not substantially alter volume search rate. The estimated reaction distance of $11 \mathrm{~mm}$ is well within the range of literature values (Buskey 1998, Kiørboe \& Bagøien 2005) and consistent with the observations of Katona $(1973,1975)$ who showed that the maximum reaction distance for $E$. affinis can be as much as $\sim 20 \mathrm{~mm}$.

Volume search rates vary substantially among species for millimeter-sized copepods and scale with copepod length raised to a power of about 2.7 (Kiørboe \& Bagøien 2005). The cephalothorax length of Eurytemora affinis (about $0.8 \mathrm{~mm}$ ) gives an expected vol- 
ume search rate of $56 \mathrm{l} \mathrm{d}^{-1}$ based on Kiørboe \& Bagoien (2005), which is outside the confidence limits of the estimated volume search rate from our study (172 \pm 961 $\mathrm{d}^{-1}$ ), and the mean is about 3 -fold smaller than in our study. This difference in estimates of volume search rate may reflect the difference in approaches between previous studies and ours. In particular, Kiørboe \& Bagøien (2005) reported no difference in volume search rate between copepods using hydromechanical signals (including Acartia) and those using pheromones, once corrected for copepod size. This difference between our study and those using behavioral approaches warrants further investigation. In any case, the effective volume search rate determined in our experiments was not low compared to values determined through observations of behavior. This suggests that the search process is the component limiting mating probability, and that the other components of mating play a relatively minor role.

In addition to the higher volume search rate in Eurytemora affinis than in Acartia hudsonica, we also found differences in the males' readiness to mate (Choi \& Kimmerer 2008). The time for half of the male E. affinis to became ready to mate was about $1.3 \mathrm{~h}$, about 6 -fold shorter than the equivalent time for $A$. hudsonica. The fraction that ultimately became ready to mate was about the same $(74 \pm 10 \%$ for $E$. affinis and $70 \pm 21 \%$ for A. hudsonica). Examination of data from only the small volumes showed that the value of $\mu$ for $A$. hudsonica was probably closer to 1 , whereas a similar analysis for $E$. affinis supported the conclusion that about a quarter of the males would never mate. The observed mishandling of spermatophores by males could contribute to the relatively high fraction of males that were estimated never to mate. However, these values were determined in rather short incubations for E. affinis, so we view these results as tentative.

The frequent spermatophore production of males has implications for population growth. Eurytemora affinis females may have limited capability to store sperm (Barthélémy et al. 1998) and appear to require repeated mating to stay fertile (e.g. Heinle 1970, Katona 1975), as has been observed in some (but not all) other copepod species (Wilson \& Parrish 1971, Berger \& Maier 2001). At low density near the critical density of the population (Fig. 4), the factor most limiting population growth would be the availability of potential mates. Encounters would be infrequent, so most copepods would be ready to mate by the time they encountered a suitable partner. However, when the population is at an intermediate level, the capability of frequent mating may increase the rate of population growth.

Sex ratio is another important factor with implications for population growth. The critical density is at a minimum for intermediate values of the sex ratio of adult copepods, and higher at higher or lower values (Eq. 2). In general, the sex ratio of field populations of Eurytemora affinis and other copepods with limited capacity to store sperm is close to 1:1 (Kiørboe 2006). Sex ratio is also influenced by environmental conditions. Conditions favoring faster development in the last nauplius stage may generally induce the development of males, and unfavorable conditions may produce more females (Takeda 1950, Alcaraz 1997, Irigoien et al. 2000). Producing more females under unfavorable conditions may increase the critical density above that based on a 1:1 sex ratio (Fig. 4, Eq. 2). However, this strategy may allow for rapid population growth when conditions improve if the females have had a chance to mate in the interim and therefore to reproduce rapidly when food becomes plentiful, as demonstrated in field studies (Tande \& Hopkins 1981, Osgood \& Frost 1994, Irigoien et al. 2000).

The population model showed that the Eurytemora affinis population could recover from densities below detection limits under some conditions. E. affinis females carried an average of $\sim 5$ eggs ind. ${ }^{-1}$ from 1984 to 1990 (Kimmerer et al. 1994), corresponding to egg production rates of 3 to 4 eggs female ${ }^{-1} \mathrm{~d}^{-1}$ at a development time of $\sim 30$ to $40 \mathrm{~h}$. More recent studies suggest a lower reproductive rate during the population declines of late spring (W. Kimmerer unpubl. data). With no mortality apart from that due to circulation, the critical density would be $\sim 0.01 \mathrm{~m}^{-3}$ (Fig. 4). A daily in situ mortality of $0.05 \mathrm{~d}^{-1}$ would result in a critical density of $\sim 0.1 \mathrm{~m}^{-3}$. To get a critical density as high as the detection limit for the summer population of $E$. affinis (Fig. 4) would require an in situ mortality rate of around $0.1 \mathrm{~d}^{-1}$. Estimates of mortality from literature results for egg-carrying copepods are around 0.15 to $0.25 \mathrm{~d}^{-1}$ at $20^{\circ} \mathrm{C}$ (Hirst \& Kiørboe 2002). Thus, with reasonable egg production and mortality rates, the critical density approaches the estimated minimum densities in the field, which were based on values from net tows (Fig. 5). Note that these data reflect conditions only since 1987 when Corbula amurensis decimated the summer phytoplankton and E. affinis began to disappear from the plankton every summer (Kimmerer et al. 1994). Before that time this species was abundant all year, so it is unlikely that E. affinis suffered low population abundance before the monitoring program started. The relationship of density in aggregations to that determined from long, integrated net tows is unknown.

Acknowledgements. We thank T. Ignoffo for laboratory assistance, K. Hieb for providing us with the zooplankton abundance data, and M. Weaver for comments on the manuscript. This research was funded by the National Science Foundation Grant OCE-0351850. 


\section{LITERATURE CITED}

Alcaraz M (1997) Copepods under turbulence: grazing, behavior and metabolic rates. Sci Mar 61:177-195

Allee WC (1931) Animal aggregations: a study in general sociology. University of Chicago Press, Chicago, IL

Ambler JW (1985) Seasonal cycles of zooplankton in San Francisco Bay. Hydrobiologia 129:177-197

Bagøien E, Kiørboe T (2005) Blind dating — mate finding in planktonic copepods. III. Hydromechanical communication in Acartia tonsa. Mar Ecol Prog Ser 300:129-133

Ban S (1992) Effects of photoperiod, temperature, and population density on induction of diapause egg production in Eurytemora affinis (Copepoda: Calanoida) in lake Ohnuma, Hokkaido, Japan. J Crustac Biol 12:361-367

- Ban S (1994) Effect of temperature and food concentration on post-embryonic development, egg production and adult body size of calanoid copepod Eurytemora affinis. J Plankton Res 16:721-735

Ban S, Minoda T (1992) Hatching of diapause eggs of Eurytemora affinis (Copepoda: Calanoida) collected from lakebottom sediments. J Crustac Biol 12:51-56

Barthélémy RM, Cuoc C, Defaye D, Brunet M, Mazza J (1998) Female genital structures in several families of Centropagoidea (Copepoda: Calanoida). Philos Trans R Soc Lond B Biol Sci 353:721-736

Berger I, Maier G (2001) The mating and reproductive biology of the freshwater planktonic calanoid copepod Eudiaptomus gracilis. Freshw Biol 46:787-794

Burkill PH, Kendall TF (1982) Production of the copepod Eurytemora affinis in the Bristol Channel. Mar Ecol Prog Ser 7:21-31

Buskey EJ (1998) Components of mating behavior in planktonic copepods. J Mar Syst 15:13-21

Castel J, Veiga J (1990) Distribution and retention of the copepod Eurytemora affinis hirundoides in a turbid estuary. Mar Biol 107:119-128

Choi KH, Kimmerer W (2008) Mate limitation in an estuarine population of copepods. Limnol Oceanogr 53:1656-1664

Corkett CJ, McLaren IA (1970) Relationships between development rate of eggs and older stages of copepods. J Mar Biol Assoc UK 50:161-168

David V, Sautour B, Chardy P, Leconte M (2005) Long-term changes of the zooplankton variability in a turbid environment: the Gironde Estuary (France). Estuar Coast Shelf Sci 64:171-184

Griffiths AM, Frost BW (1976) Chemical communication in the marine planktonic copepods, Calanus pacificus and Pseudodiaptomus sp. Crustaceana 30:1-9

Hairston NG Jr, Dillon TA, Stasio BTD Jr (1990) A field test for the cues of diapause in a freshwater copepod. Ecology 71: $2218-2223$

Heinle DR (1970) Population dynamics of exploited cultures of calanoid copepods. Helgol Mar Res 20:360-372

> Hirst AG, Kiørboe T (2002) Mortality of marine planktonic copepods: global rates and patterns. Mar Ecol Prog Ser 230:195-209

Hopp U, Maier G (2005) Survival and development of five species of cyclopoid copepods in relation to food supply: experiments with algal food in a flow-through system. Freshw Biol 50:1454-1463

$>$ Hough AR, Naylor E (1991) Field studies on retention of the planktonic copepod Eurytemora affinis in a mixed estuary. Mar Ecol Prog Ser 76:115-122

Irigoien X, Obermueller B, Head RN, Harris RP and others (2000) The effect of food on the determination of sex ratio in Calanus spp.: evidence from experimental studies and field data. ICES J Mar Sci 57:1752-1763

Katona SK (1973) Evidence for sex pheromones in planktonic copepods. Limnol Oceanogr 18:574-583

$>$ Katona SK (1975) Copulation in the copepod Eurytemora affinis. Crustaceana 28:89-95

Kimmerer WJ (2004) Open-water processes of the San Francisco Estuary: from physical forcing to biological responses. San Francisco Est Watershed Sci 2, Article 1. Available at: http://repositories.cdlib.org/jmie/sfews/vol2/ iss1/art1/

> Kimmerer WJ (2006) Response of anchovies dampens effects of the invasive bivalve Corbula amurensis on the San Francisco Estuary foodweb. Mar Ecol Prog Ser 324:207-218

Kimmerer WJ, Orsi JJ (1996) Causes of long-term declines in zooplankton in the San Francisco Bay estuary since 1987. Hollibaugh JT (ed) San Francisco Bay: the ecosystem. The American Association for the Advancement of Science, San Francisco, CA, p 403-424

Kimmerer WJ, Gartside E, Orsi JJ (1994) Predation by an introduced clam as the likely cause of substantial declines in zooplankton of San Francisco Bay. Mar Ecol Prog Ser 113:81-93

Kiørboe T (2006) Sex, sex-ratios, and the dynamics of pelagic copepod populations. Oecologia 148:40-50

Kiørboe T (2007) Mate finding, mating, and population dy namics in a planktonic copepod Oithona davisae: there are too few males. Limnol Oceanogr 52:1511-1522

Kiørboe T, Bagøien E (2005) Motility patterns and mate encounter rates in planktonic copepods. Limnol Oceanogr 50:1999-2007

Liang D, Uye S (1996) Population dynamics and production of the planktonic copepods in a eutrophic inlet of the inland sea of Japan. II. Acartia omorii. Mar Biol 125:109-117

> Marcus NH (1980) Photoperiodic control of diapause in the marine calanoid copepod Labidocera aestiva. Biol Bull 159:311-318

- Meng L, Orsi JJ (1991) Selective predation by larval striped bass on native and introduced copepods. Trans Am Fish Soc 120:187-192

Nichols FH, Thompson JK, Schemel LE (1990) Remarkable invasion of San Francisco Bay (California, USA) by the Asian clam Potamocorbula amurensis. II. Displacement of a former community. Mar Ecol Prog Ser 66:95-101

Norrbin MF (1994) Seasonal patterns in gonad maturation, sex ratio and size in some small, high-latitude copepods: implications for overwintering tactics. J Plankton Res 16: $115-131$

> Osgood KE, Frost BW (1994) Comparative life histories of three species of planktonic calanoid copepods in Dabob Bay, Washington. Mar Biol 118:627-636

Peitsch A, Köpcke B, Bernat N (2000) Long-term investigation of the distribution of Eurytemora affinis (Calanoida; Copepoda) in the Elbe estuary. Limnologica 30:175-182

> Santer B (1998) Life cycle strategies of free-living copepods in fresh waters. J Mar Syst 15:327-336

Takeda N (1950) Experimental studies on the effect of external agencies on the sexuality of a marine copepod. Physiol Zool 23:288-301

Tande KS, Hopkins CCE (1981) Ecological investigations of the zooplankton community of Balsfjorden, northern Norway: the genital system in Calanus finmarchicus and the role of gonad development in overwintering strategy. Mar Biol 63:159-164

- Thorp JH, Casper AF (2003) Importance of biotic interactions in large rivers: an experiment with planktivorous fish, dreissenid mussels and zooplankton in the St. Lawrence River. River Res Appl 19:265-279 
Tiselius P, Hansen B, Jonsson P, Kiørboe T, Nielsen TG, Piontkovski S, Saiz E (1995) Can we use laboratory-reared copepods for experiments? A comparison of feeding behaviour and reproduction between a field and a laboratory population of Acartia tonsa. ICES J Mar Sci 52: 369-376

Uye SI (1985) Resting egg production as a life history strategy of marine planktonic copepods. Bull Mar Sci 37:440-449

van Leeuwen HC, Maly EJ (1991) Changes in swimming behavior of male Diaptomus leptopus (Copepoda: Calanoida) in response to gravid females. Limnol Oceanogr

Editorial responsibility: William Peterson,

Newport, Oregon, USA
36:1188-1195

Venables WN, Ripley BR (2003) Modern applied statistics with S, 4th edn. Springer-Verlag, New York

Walters RA, Cheng RT, Conomos TJ (1985) Time scales of circulation and mixing processes of San Francisco Bay waters. Hydrobiologia 129:13-36

Wilson DF, Parrish KK (1971) Remating in a planktonic marine calanoid copepod. Mar Biol 9:202-204

Yen J, Weissburg MJ, Doall MH (1998) The fluid physics of signal perception by mate-tracking copepods. Philos Trans R Soc Lond, B 353:787-804

Submitted: July 24, 2008; Accepted: November 4, 2008

Proofs received from author(s): February 22, 2009 